\title{
CONTINUOUS FIBER POLYMER COMPOSITES FOR THERMAL APPLICATIONS
}

\author{
Yehia Elsayed, Ahmed Elkholy, Garrett Melenka and Roger Kempers \\ Department of Mechanical Engineering \\ York University \\ Toronto, Canada \\ kempers@yorku.ca
}

\begin{abstract}
This paper presents an analytical investigation into the effective thermal conductivity of 3D printed continuous fibre polymer composites (CFPCs) using rule of mixture micro-structural analysis. Two fused deposition modelling techniques were utilized using a off-the-shelf printer and a low-cost modified printer. Results demonstrate significant improvement in the effective thermal conductivity of the composite compared to the base polymer. One samples was experimentally tested to examine the veracity of the model predictions.
\end{abstract}

Keywords-component; Continuous fibre; continuous wire Conductive polymers; Thermal Properties, $3 D$ printing

\section{BACKGROUND AND LITERATURE}

Conductive polymer composites (PC) are utilized in many applications such as heat exchangers because they can offer relatively moderate thermal conductivity in addition to the advantages of light weight, corrosion resistance and low cost. These advantages result in a convenient choice for water desalination and electronic cooling applications [1],[2]. The performance of heat exchangers can be enhanced by increasing the thermal conductivity of the material, adding convective surface area, or increasing the convective heat transfer coefficient through shape complexity and turbulent generators.

Additive manufacturing (AM) techniques such as fused deposition modeling (FDM) can be employed in conjunction with PC to create more complex and effective heat exchangers [3],[4]. The addition of metal and reinforcement or other reinforcing materials such as carbon fiber, graphite and carbon nanotubes can increase the thermal conductivity of the material [5],[6]. However, the discontinuous nature of the reinforcement materials is believed to limit conductivity improvement where the interfacial resistances become dominant specifically at low reinforcement percentages[7],[8].

Recently, continuous fiber AM gained more attention due to the improved stiffness that can be achieved [9],[10]. Modified and commercial printers were used to investigate the mechanical properties of continuous fiber polymer composites (CFPCs) structures printed with reinforcement materials such as carbon, Kevlar® and glass fibers [11]-[13]. Presently, the thermal properties of CFPCs have not been studied despite the advantages that can be offered.

This study analytically investigates the thermal conductivity of AM CFPCs using two different printing techniques. The first method uses a commercial continuous fiber $3 \mathrm{D}$ printer to examine the effect of carbon fiber layers on overall thermal conductivity of the produced composite material. Secondly, a modified conventional FDM 3D printer was used which embeds continuous fibers within the printed structure. In the current stage, continuous metal wires are used as the reinforcing material. The goal of this work is to use high conductivity fibers such as continuous pitch-based carbon fibers and carbon nanotube yarns to produce highly conductive polymer composite structures.

\section{METHODOLOGY}

Two 3D printing machines were used in this work. The first 3D printer is the commercially available printer (MarkOne, MarkForged, Somerville, MA) which can print CFPCs using dual extruders, one for the polymer matrix and the other for continuous reinforcing fibers. Although Markforged printers can print different types of fibers such as carbon fibers, Kevlar and glass fibers with high reinforcement volumes, it is believed that the thermal conductivity of these fibers is relatively low compared to ultra-high conductive fibers such as the pitch-based carbon fibers. This will degrade the overall thermal conductivity of the CFPCs due to the existence of the polymer. On the other hand, the method described by Elsayed et al. [14] utilize an open-source, modified 3D printer with a single extruder combines polymer with more conductive continuous reinforcements such as Nickel chromium and copper wires within the printed structure. It may be possible to achieve higher overall thermal conductivity with the CFPCs printed with modified printer than the MarkForged components even with lower reinforcement volumes. 


\section{A. Samples Description}

\section{1) MarkForged samples}

To evaluate the thermal conductivity of CFPCs, six samples of different carbon fiber reinforcement volume fractions samples were designed and printed using a commercial CFPC printer (MarkOne, MarkForged, Somerville, MA) and Nylon as the base matrix. Figure 1 shows and example sample geometry, dimensions and fibers layer configuration. Sample geometry was created using computer aided design software (SolidWorks 2017 SP4.0, Dassault Systems, and uploaded to the online based slicing software (Eiger 1.2, MarkForged, Somerville, MA). The software provides information about the total number of fibers and nylon layers in the printed samples which can be used to deduce fiber volume fraction $\left(v_{f}\right)$. Table 1 shows sample dimensions and predicted fiber volume fraction by the software. Fibers printing angle was set to zero degree while two build directions were used to investigate the thermal conductivity in the axial and transverse directions of the fibers (Table 1). The physical properties of the $0.375 \mathrm{~mm}$ carbon fiber filament manufactured by MarkForged were not provided by the supplier. However, it is assumed that the fiber filament is a combination of polyacrylonitrile (PAN) based carbon fibers and polymeric material that give the filament the apparent stiffness. With this assumption, the mechanical properties and thermal conductivity of these fibers can be inferred.

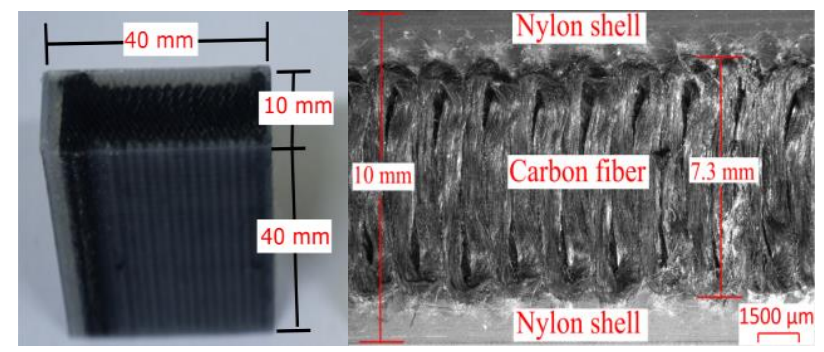

Figure 1. Carbon fiber reinforced sample (0-degree fiber printing angle) Left: sample with dimensions 40x40x25mm. Right: microscope image showing the continuous fiber.

TABLE 1 SAMPLES DIMENSION AND FIBER VOLUME FRACTION

\begin{tabular}{|c|c|c|c|}
\hline $\begin{array}{c}\text { Sample } \\
\text { No. }\end{array}$ & $\begin{array}{c}\text { Sample dimensions } \\
(\mathbf{L} \times \mathbf{W} \times \mathbf{~ H})(\mathbf{m m})\end{array}$ & $\begin{array}{c}\text { Fiber printing } \\
\text { angle }\end{array}$ & $\begin{array}{c}\text { Fiber volume } \\
\text { fraction }\left(\boldsymbol{v}_{f}\right) \boldsymbol{\%}\end{array}$ \\
\hline 1 & $40 \times 10 \times 40$ & 0 & 79 \\
\hline 2 & $40 \times 10 \times 40$ & 0 & 55 \\
\hline 3 & $40 \times 10 \times 40$ & 0 & 31 \\
\hline 4 & $40 \times 40 \times 10$ & 0 & 76 \\
\hline 5 & $40 \times 40 \times 10$ & 0 & 63 \\
\hline 6 & $40 \times 40 \times 10$ & 0 & 51 \\
\hline
\end{tabular}

\section{2) Modified printer samples}

A FDM printer (Prusa i3, Prusa Research, Czech Republic) was modified to create CFPC components. Six samples of CFPCs were designed using the method described by Elsayed et al [14] where Polylactic acid (PLA) filament $(1.75 \mathrm{~mm}$, Spool 3d, Canada) was fused through the printing nozzle and combined with Nickel-chromium wires (75 um, McMaster Carr, Ohio, USA), copper wires (75 um, Remington Industries, Canada) and Pitch carbon fiber (Mitsubishi Chemicals Carbon Fiber and Composites, California, USA) to create CFPC samples. Figure 2 shows a Nickel chromium reinforced prototype sample with the geometry, dimensions and reinforcement configuration. The prototype sample was printed using $0.6 \mathrm{~mm}$ diameter nozzle, $0.4 \mathrm{~mm}$ layer height and 180 degrees Celsius printing temperature. Sample printing code was generated using a custom script (MATLAB, Mathworks, Natick, MA), where the printing angle was set to zero to investigate the thermal conductivity in the axial and transverse directions by changing the build direction of the samples.

Table 2 shows samples dimensions and the nominal reinforcement volume fraction calculated from the input printing parameters.

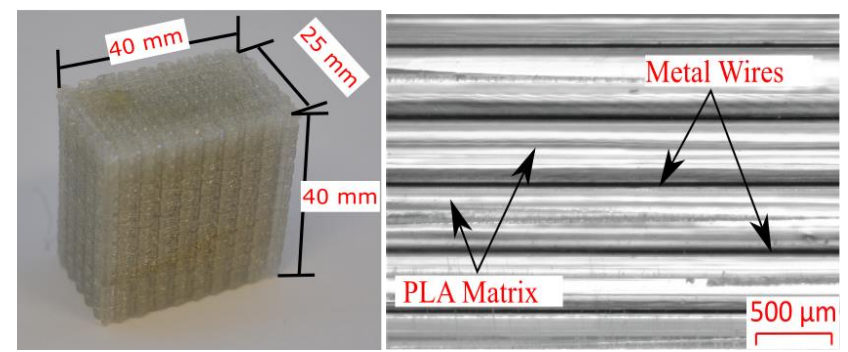

Figure 2. Prototype sample for the modified printer Left: sample with dimensions 40x40x25mm. Right: microscope image showing the continuous reinforced metal wires.

TABLE 2 SAMPLES DIMENSIONS AND REINFORCEMENT VOLUME FRACTION

\begin{tabular}{|c|c|c|c|c|}
\hline $\begin{array}{c}\text { Sample } \\
\text { No. }\end{array}$ & $\begin{array}{c}\text { Sample } \\
\text { Dimensions } \\
(\mathrm{L} \times \mathrm{W} \times \mathrm{H}) \\
(\mathrm{mm})\end{array}$ & $\begin{array}{c}\text { Reinforcement } \\
\text { material }\end{array}$ & $\begin{array}{c}\text { Reinforcement } \\
\text { printing angle }\end{array}$ & $\begin{array}{c}\text { Reinforcement } \\
\text { volume } \\
\text { fraction }\left(v_{f}\right) \%\end{array}$ \\
\hline 7 & $40 \times 10 \times 40$ & $\begin{array}{c}\text { Nickel } \\
\text { chromium }\end{array}$ & 0 & 1.7 \\
\hline 8 & $40 \times 10 \times 40$ & $\begin{array}{c}\text { Copper } \\
\text { fiber }\end{array}$ & 0 & 1.7 \\
\hline 9 & $40 \times 10 \times 40$ & $\begin{array}{c}\text { Pitch carbon } \\
\text { Nickel } \\
\text { chromium }\end{array}$ & 0 & 1.7 \\
\hline 7 & $40 \times 40 \times 10$ & $\begin{array}{c}\text { Copper } \\
\text { fiber }\end{array}$ & 0 & 1.7 \\
\hline 12 & $40 \times 40 \times 10$ & $\begin{array}{c}\text { Pitch carbon } \\
\text { fiber }\end{array}$ & 0 & 1.7 \\
\hline
\end{tabular}

\section{B. Experimental setup}

Different apparatuses are being used for characterizing materials thermal conductivity based on different operating concepts. The steady state and the transient apparatuses families are the most commonly used. Based on the nature of the material being measured and the rang of the thermal conductivity, a convenient apparatus can be chosen. A steady state thermal test apparatus was used to assess the thermal conductivity of the CFPC samples. The employed test rig belongs to the steady state category which mainly depends on 
transferring heat through the sample and measuring the resultant temperature difference across the sample at steady state conditions. Similar apparatuses were used for measuring thermal conductivity of thermal interface materials[15] and conductive polymers [16]. Fig. 3 shows that the apparatus consists of two sides; one for supplying the heat and the other one represents the sink. Each side consists of two isothermal blocks; one is the main one while the other working as a guard for it. The main block of the hot side has a dimension of 40 $\mathrm{mm} \times 40 \mathrm{~mm} \times 6.35 \mathrm{~mm}$ while the guard one is $70 \mathrm{~mm} \times 70$ $\mathrm{mm} \times 15.7 \mathrm{~mm}$ and has a groove which allows the main to be fixed inside. Its function is to guarantee that all the heat coming from the main heater is going into the sample and eliminate any losses from the main heater sides. This was done by tuning its power until reaching a temperature that follow the main heater temperature. Isothermal conditions for all parts were achieved by manufacturing them from copper material, $\mathrm{k}=391.2 \mathrm{w} / \mathrm{m} \mathrm{k}$, to produce a uniform temperature field inside it. Moreover, this was validated using numerical simulation. The temperature of both blocks was observed at three different locations where each sensor from the main block is opposite to its analogous one from the guard block. It was postulated that the secondary power is convenient when the temperature difference between each pair did not exceed $0.001{ }^{\circ} \mathrm{C}$ at steady-state. Also, it was assumed that the steady state conditions were reached when the time gradient of the temperature for each sensor is less than 0.00001 .

The cold side main block has a dimension of $40 \mathrm{~mm} \times 40$ $\mathrm{mm} \times 12$, while the secondary one is $80 \mathrm{~mm} \times 80 \mathrm{~mm} \times 12$ $\mathrm{mm}$. All the blocks and the sample are clamped together against a force gauge. The specimen was manufactured with small thickness to have a negligible heat loss from its side and to verify that the heat flow is one-dimensional. Furthermore, all parts were wrapped by silica aerogel insulating material having a thermal conductivity of $0.014 \mathrm{w} / \mathrm{m} \mathrm{k}$.

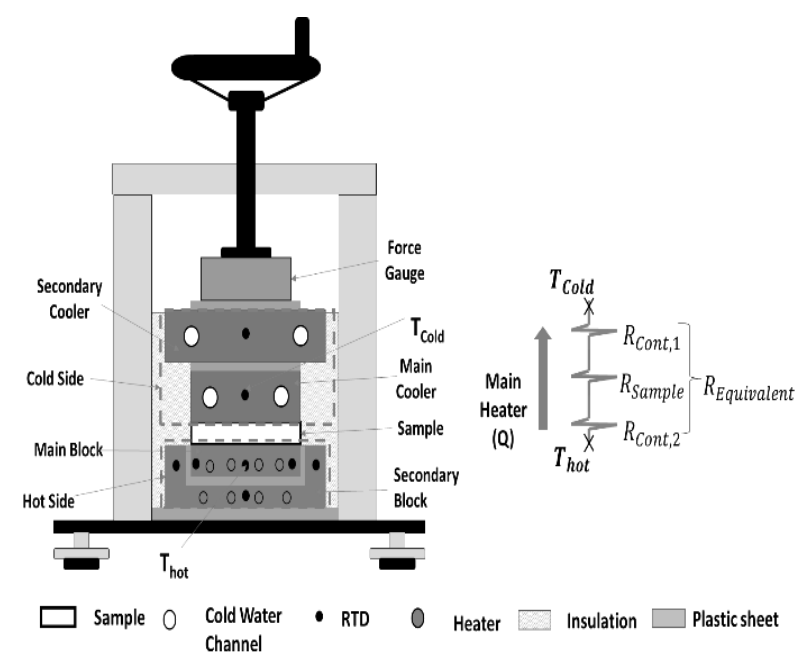

Figure 3. Experimental setup for measuring the thermal conductivity.

The thermal conductivity is calculated using the Fourier conduction equation as follows;

$$
k=\frac{Q \Delta t}{A_{c}\left(T_{\text {hot }}-T_{\text {cold }}\right)}
$$

where $k$ is the tested thermal conductivity, $\Delta t$ is the sample thickness, $A_{c}$ is the cross-section area and $\left(T_{h}-T_{c}\right)$ is the temperature difference across the sample.

\section{MICROSCOPY}

The internal structure of the CFPC samples was examined using stereo-microscope (MZ10 F, Leica, Concord, Ontario). Samples produced using the MarkForged 3D printer and modified printer were examined to investigate the difference between the reinforcement volume fraction given by the software and the actual reinforcement fraction assessed by image processing. Fiber volume fraction measurements are necessary for accurate predication of the thermal and mechanical properties. The samples were sectioned perpendicular to the reinforcement axis using a high-speed abrasive cutting wheel. Thereafter, the samples went through four steps of grinding and polishing using 240, 400, 600 and 1200/4000- grit silicon carbide discs to get a convenient surface for microscopy. Figure 4 shows the cross-sectional microscopy of the two samples showing reinforcement and polymer layers with the air voids existing due to the nature of FDM printing technique. Image processing was performed using image analysis software (ImageJ, National Institutes of Health, Bethesda, Maryland, USA) to measure reinforcement volume fraction across the two samples. For the MarkForged Sample no. 3 the analysis showed $46.7 \%$ of fiber volume fraction exist in the sample compared to $31 \%$ calculated using the Eiger software. For the custom metal reinforced samples, the analysis determined $1.48 \%$ fiber volume fraction compared to $1.7 \%$ calculated from the input printing parameters for the modified printer prototype sample.

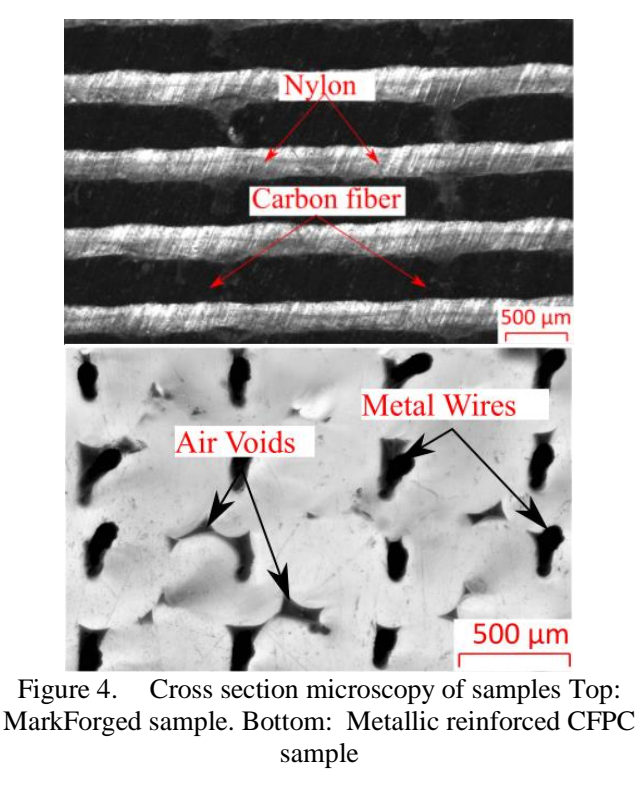


Additionally, a single fiber filament (Carbon Fiber CFF, Markforged, Somerville, MA) used for printing the fiber layers in the Markforged samples was examined under the microscope to evaluate the percentage of the carbon fibers and the polymeric material. Figure 5 shows the filament cross-section at three different positions. It was noticed that the filament was not completely filled with fibers and that the fibers configuration within the filament is not fixed which strengthen the possibility that the fibers are not fully continuous inside the filament. Image processing was performed again and a value of $35.5 \%$ of fibers was found within the fiber filament. The value obtained reduces the overall fiber percentage predicted by the software and the one from the image processing of the sample cross section.

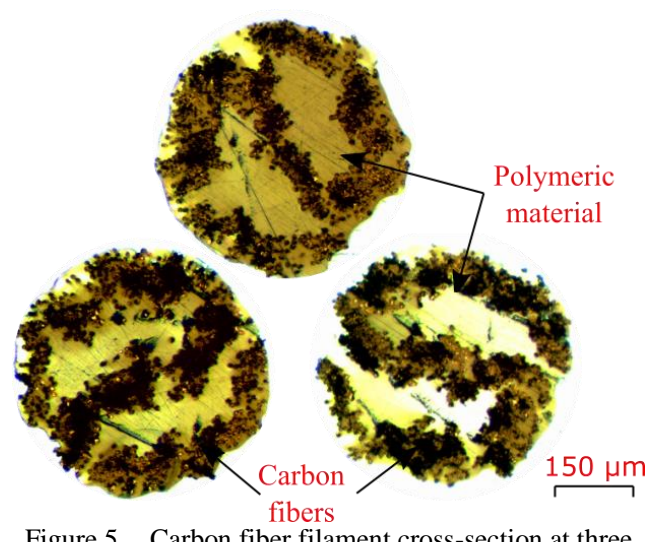

Figure 5. Carbon fiber filament cross-section at three different positions

\section{ANALYTICAL MODEL}

Different analytical models are available for the prediction of composites material thermal conductivity [17]. Depending on the reinforcement shape, orientation and measurement direction, considerably accurate models can be deduced. One basic model for composites properties description is the rule of mixture.

The reinforcement configurations addressed here are shown in Fig. 6. Here the samples consist of continuous unidirectional reinforcements which allows the straightforward rule of mixture model to be used. This model describes composite properties as a function of constitutes properties and reinforcement volume fraction. For CFPCs, rule of mixture can take simple forms of parallel and series models shown in Eqs. 2 and 3, respectively. Where $\mathrm{k}_{c}, \mathrm{k}_{\mathrm{p}}$ and $\mathrm{kf}_{\mathrm{f}}$ are composite, polymer and fiber thermal conductivity respectively while $\emptyset$ is fiber volume fraction. The main limitation for the rule of mixture model in this case is over estimation that can occur due to the neglection of the interfacial resistances especially for the series model.

$$
\begin{gathered}
k_{c}=(1-\emptyset) k_{p}+\emptyset k_{f} \\
k_{c}=\left(\frac{1-\emptyset}{k_{p}}+\frac{\emptyset}{k_{f}}\right)^{-1}
\end{gathered}
$$

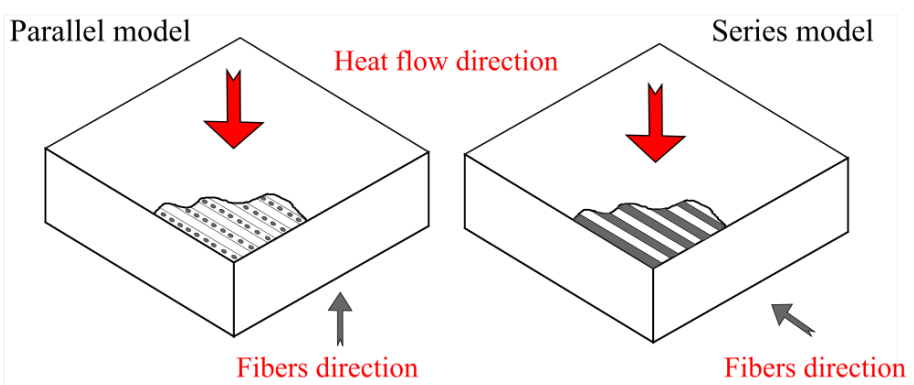

Figure 6. Parallel and series models

Constituents' properties can greatly affect CFPCs overall thermal conductivity. Different reinforcement materials are applied to the model to study the effect of ultra-high conductive reinforcements such as copper and Pitch based carbon fiber on the overall thermal conductivity. Again, the carbon fiber provided by Markforged is believed to be PAN based with relatively low thermal conductivity compared to metal reinforcements. Assumed values for thermal properties provided from [18], [19] shown in Table 3 are used in the thermal conductivity evaluation as there is insufficient information about the thermal properties from the suppliers.

TABLE 3 MATERIALS THERMAL PROPERTIES [18], [19]

\begin{tabular}{|c|c|}
\hline Material & Thermal Conductivity (W/m.K) \\
\hline Nylon & $0.3[18]$ \\
\hline PAN Carbon fiber & $8[19]$ \\
\hline PLA & $0.29[18]$ \\
\hline Nickel chromium & $13[18]$ \\
\hline Copper & $385[18]$ \\
\hline Pitch carbon fiber & $500[19]$ \\
\hline
\end{tabular}

\section{RESULTS AND DISCUSSION}

Using the rule of mixture model described in Section IV, analytically predicted values for the overall thermal conductivity were obtained for both the commercial and modified 3D printers. Samples 1-3 and 7-9 thermal conductivity was predicted using the parallel model in "(2)" as the continuous reinforcement is parallel to the heat flow direction while the series model in "(3)" was utilized for samples 4:6 and 10:12 as the heat flows transversely through the reinforcement. Figure 6 shows the results for the Markforged samples described in Table 1. A maximum value of $6.42 \mathrm{~W} / \mathrm{m} \cdot \mathrm{K}$ was found for sample no. 1 with $79 \%$ nominal fibers content when the thermal conductivity is predicted in the axial direction of the fibers. However, this value drops to $2.8 \mathrm{~W} / \mathrm{m} \cdot \mathrm{K}$ when the actual fiber content obtained from the fiber filament microscopy is used assuming that the matrix material in the filament has the same thermal conductivity as Nylon. As well, the thermal conductivity is predicted in the transverse direction where low thermal conductivity (1.13 $\mathrm{W} / \mathrm{m} \cdot \mathrm{K}$ ) was obtained even with $76 \%$ nominal fibers content 
in sample no. 4. The modified printer samples, described in Table 2, showed higher thermal conductivity using copper wires and Pitch carbon fibers (samples 8 and 9) even with as low reinforcement volume fraction as $1.7 \%$ (Figure 7 ). This means that the modified printer is more convenient for creating increasingly conductive CFPCs. The overall thermal conductivity of the CFPCs made by the Markforged printers can be significantly improved if Pitch-based carbon fibers are used due to their high thermal conductivity. Meanwhile for the customized printer, further modification that can increase the reinforcement volume fraction will boost the overall thermal conductivity of the prints. For the experimental results, sample no. 1 was tested using the previously mentioned setup. A value of $1.84 \mathrm{~W} / \mathrm{m} \cdot \mathrm{K}$ was found for the thermal conductivity. The deviation between the measured value and the value predicted by the model with actual fiber content is believed to be caused by uncertainty in the fibers grade and conductivity. Additionally, the possibility that the fibers are not fully continuous within the samples inferred from the filament cross-section in Figure 5 can cause the thermal conductivity to drop. Future work will focus on experimental testing of the rest of the samples to examine the compatibility of the analytical models with the printed samples and increasing fiber volume fraction of the modified printer to achieve higher thermal conductivity.

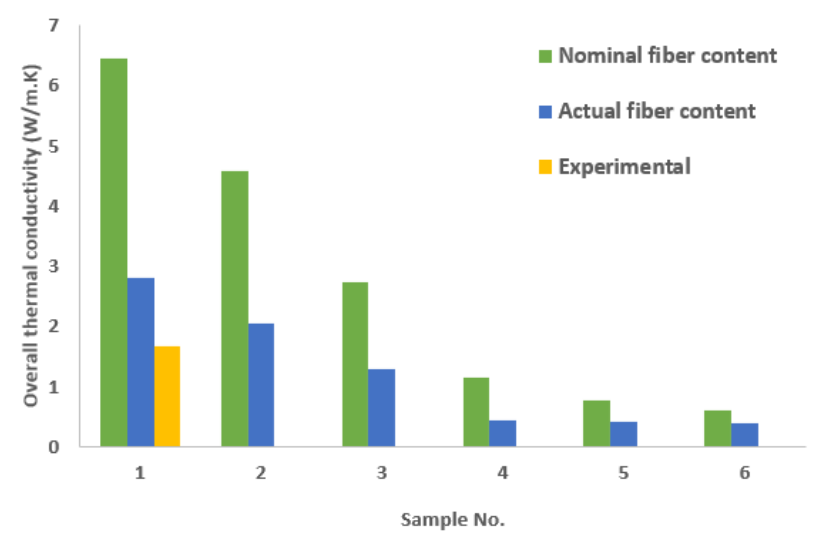

Figure 6. Overall thermal conductivity of Markforged samples

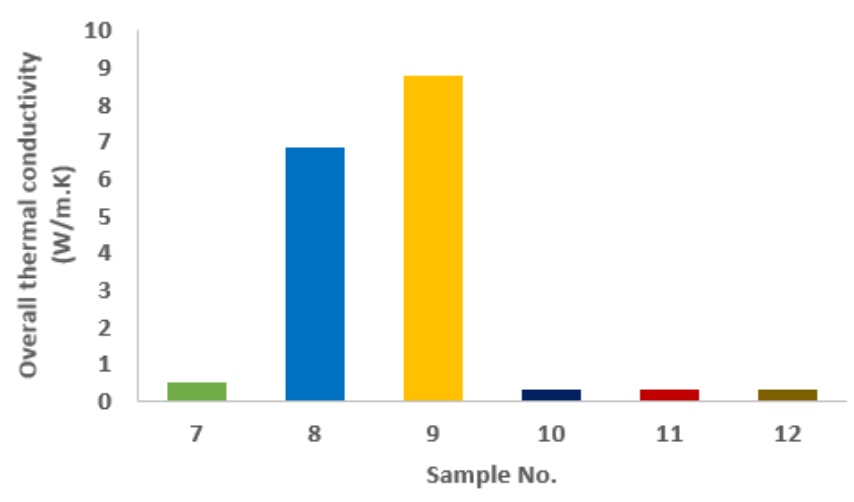

Figure 7. Overall thermal conductivity of the modified printer samples

\section{CONCLUSIONS}

CFPCs can be an attractive choice for thermal applications like heat exchangers by utilizing conductive fibers. Additive manufacturing combined with fiber reinforcement can be used to generates sufficient heat transfer coefficients for thermal applications. The high overall thermal conductivity values showed in this study makes CFPCs comparable to moderate conductive metals such as stainless steel which make it convenient for heat exchanging applications especially for corrosive fluids.

\section{REFERENCES}

[1] Q. Wang, X. H. Han, A. Sommers, Y. Park, C. T'Joen, and A. Jacobi, "A review on application of carbonaceous materials and carbon matrix composites for heat exchangers and heat sinks," Int. J. Refrig., vol. 35, no. 1, pp. 7-26, 2012.

[2] T. B. Scheffler and A. J. Leao, "Fabrication of polymer film heat transfer elements for energy efficient multi-effect distillation," Desalination, vol. 222, no. 1-3, pp. 696-710, 2008.

[3] J. H. K. Haertel and G. F. Nellis, "A fully developed flow thermofluid model for topology optimization of 3D-printed air-cooled heat exchangers," Appl. Therm. Eng., vol. 119, pp. 10-24, 2017.

[4] J. Cevallos, A. Bar-Cohen, and D. C. Deisenroth, "Thermal performance of a polymer composite webbed-tube heat exchanger," Int. J. Heat Mass Transf., 2016.

[5] U. Kalsoom, A. Peristyy, P. N. Nesterenko, and B. Paull, “A 3D printable diamond polymer composite: a novel material for fabrication of low cost thermally conducting devices," RSC Adv., vol. 6, no. 44, pp. 38140-38147, 2016.

[6] M. Nikzad, S. H. Masood, and I. Sbarski, "Thermomechanical properties of a highly filled polymeric composites for Fused Deposition Modeling," Mater. Des., vol. 32, no. 6, pp. 3448-3456, 2011.

[7] T. Flaata, G. J. Michna, and T. Letcher, "Thermal Conductivity Testing Apparatus for 3D Printed Materials," in ASME 2017 Summer Heat Transfer Conference, 2017, no. August, p. HT2017-4856. 
[11] G. W. Melenka, B. K. O. Cheung, J. S. Schofield, M. R. Dawson, and J. P. Carey, "Evaluation and prediction of the tensile properties of continuous fiberreinforced 3D printed structures," Compos. Struct., vol. 153, pp. 866-875, 2016.

[12] A. N. Dickson, J. N. Barry, K. A. Mcdonnell, and D. P. Dowling, "Fabrication of continuous carbon, glass and Kevlar fibre reinforced polymer composites using additive manufacturing," Addit. Manuf., vol. 16, pp. 146-152, 2017.

[13] Q. Hu, Y. Duan, H. Zhang, D. Liu, B. Yan, and F. Peng, "Manufacturing and 3D printing of continuous carbon fiber prepreg filament," J. Mater. Sci., vol. 53, no. 3, pp. 1-12, 2017.

[14] Y. Elsayed, Garrett W. Melenka, Roger Kempers, "Fabrication and Tensile Testing of 3D Printed Continuous Wire Polymer Composites," pp. 2-2, 2017.

[15] R. Kempers, P. Kolodner, A. Lyons, and A. J. Robinson, "A high-precision apparatus for the characterization of thermal interface materials," Rev. Sci. Instrum., vol. 80, no. 9, pp. 1-11, 2009.

[16] T. Letcher, "Thermal Conductivity Testing Apparatus for 3D Printed Materials THERMAL CONDUCTIVITY TESTING APPARATUS FOR 3D PRINTED MATERIALS," no. July, 2017.

[17] H. Chen et al., "Thermal conductivity of polymerbased composites: Fundamentals and applications," Prog. Polym. Sci., vol. 59, pp. 41-85, 2015.

[18] MATWEB, "Material properties by MATWEB," 2017. [Online]. Available: http://www.matweb.com.

[19] M. Srinivasan, P. Maettig, K. W. Glitza, B. Sanny, and A. Schumacher, "Out of Plane Thermal Conductivity of Carbon Fiber Reinforced Composite Filled with Diamond Powder," Open J. Compos. Mater., vol. 6, no. April, pp. 41-57, 2016. 